\title{
A Literatura Norteamericana no Brasil
}

Convido a que me acompanhem num vôo rápido ao estado de $\mathrm{Mi}$ nas Gerais do fim do século dezoito. Sem dúvida nos teria acontecido ouvir, numa taberna qualquer, de Vila Rica, digamos, um jovem animado, asseverar orgulhosamente que "o País de Minas Gerais era o melhor do Mundo" e devia ser "uma república livre e florescente como a dos americanos ingleses." $\mathrm{E}$ si pudêssemos ter acompanhado êsse profeta dinâmico nas suas peregrinações febrís duma a outra povoação mineira, o teriamos ouvido repetir muitas vêzes, em casas particulares, quarteis e ondequer que houvesse público, a sua crença de que Minas Gerais "podia bem ficar independente assim como faz a América inglesa." Mas sabemos quem, já há mais de um século e meio, no interior da região-berço da Independência do Brasil, vinha incitando seus conterrâneos a que seguissem o exemplo então recente da jovem república do norte. Refiro-me ao alferes Joaquim José da Silva Xavier, mártir da Inconfidência Mineira, mais devotamente lembrado pelo nome célebre de "Tiradentes." Ele estava planejando o establecimento dum govêrno republicano, conspiração malograda que the ia custar a vida.

Sabe-se que para Tiradentes a emancipação dos Estados Unidos passou a ser quase uma obsessão que êle nunca perdeu o ensêjo de invocar. Também é sabido que levava consigo, em suas viagens a cavalo, um livro que, pode dizer-se, constituiu um dos primeiros laços entre o Brasil e os Estados Unidos. Escrito em francês, e publicado na Suiça em 1778, o título reza em português: Coleção das leis constitutivas dos Estados Unidos da América, acompanhada da Declaração da Independência e de outros atos do Congreso Geral. 
E sabemos que Tiradentes procurava amigos, pedindo-lhes que traduzissem capítulos dêsse livro como também dos livros ingleses "que diziam respeito a coisas da América." 1 Graças, pois, a essa obra em francês, um de nossos primeiros monumentos literários -a $D e$ claração da Independência - transmitiu sua mensagem aos próceres dum Brasil que aspirava libertar-se das cadeias lusitanas. Não sabemos se já naquela época tinham sido traduzidos ou publicados em português quaisquer dêsses documentos constitucionais norteamericanos $;^{2}$ mas é certo que os mesmos influiram poderosamente sôbre algumas das figuras mais ilustres daquela página gloriosa da história do Brasil, o que é manifesto nas frequentes referências à emancipação americana nos depoimentos da Inconfidência Mineira de 1789. Remonta, pois, à época de Tiradentes, o comêço das relações intelectuais e culturais entre o Brasil e os Estados Unidos da América do Norte.

Voltemos agora a nossos dias para verificar até que ponto elas se têm intensificado, depois de tão dramáticamente iniciadas.

Examinemos a Bibliografia de obras norteamericanas en tradução portuguesa, complemento dêste trabalho e companheira de outra, também de minha autoria, sôbre obras norteamericanas em tradução espanhola, publicađa em 1944, em tiragem especial da $R e-$ vista iberoamericana. Vejamos, por exemplo, quais os livros norteamericanos mais lidos no Brasili, nos últimos anos.

Parece-nos que o brasileiro, profundamente grato pela bela lição Iepublicana acima referida, esforçã-se agora em estreitar ainda mais os laços que nos unem, especialmente os de natureza humana e pessoal. Traduzida para o português pela primeira vez em 1939, em seis anos uma obra de Dale Carnegie atingiu doze ediçóes, como consequência do intenso desêjo de nossos vizinhos de saber Como fazer amigos e influenciar pessoas! Nenhum outro livro americano alcançara tanta popularidade, em prazo tão curto.

Outros livros muito procurados nêstes últimos anos - alem de nossos clássicos, Poe, Twain, Franklin e de nossos romances policiais, também as aventuras de Edgar Rice Burroughs ou as do grande atirador do Far West, o célebre Buffalo Bill, e as incomparáveis creações de Disney ${ }^{3}$ - são os seguintes: Thurston Scott Welton, Método moderno da limitação dos filhos. 1 ed. 1938 - 7 ed. 1946; Isadora Duncan, Minha vida. 2 ed. 1938 - 5 ed. 1945; Margaret 
Mitchell, E o vento levou. 1 ed. 1939 - 4 ed. 1945; e Paul de Kruif, Caçadores de micróbios. 3 ed. 1945. Como fazer fortuna (Think and grow rich) de Napoleon Hill entrou em segunda impressão em 1946, precedido de Em busca do amor por Marie Jenney Howe em 1943. Só chamo a atenção sôbre êstes como exemplos de livros que têm passado por várias edições no Brasil -- e não como amostra do gôsto estético do brasileiro, gôsto que é muito variado e compreensivo.

Seria difícil definir ou delimitar o interesse do brasileiro pelo livro norteamericano ${ }^{4}$ nêstes últimos seis anos. Si evidencia interesse pelo romance social de um Steinbeck, digamos, mostra igual interesse pelos tratados político-econômicos de un Roosevelt ou Wallace. Quer manter-se em dia com os acontecimentos internacionais através da leitura de Trinta segundos sôbre Toquio de Ted W. Lawson, A politica exterior dos Estados Unidos de Walter Lippman, e $A$ alemanha por dentro de Louis P. Lochner. Muitos médicos têm-se formado aquí - e um dos resultados é evidente no crescente número de obras médicas traduzidas em português e impressas em prelos brasileiros. O Brasil está acelerando o ritmo de sua industrialização e procura nossos livros científicos para facilitar o ensino e preparo de seus futuros técnicos. Mas também é urgente uma solução para muitos problemas agrícolas - e a resposta vem do Ministério da Agricultura com um extenso programa, de traduções de mais de cem panfletos entre os publicados pelo nosso próprio Department of Agriculture. O Govêrno brasileiro lança um programa de treinamento de seu próprio pessoal; o DASP (Departamento Administrativo do Serviço Público) considera uma fase básica do programa a tradução de uma série de nossos melhores estudos sôbre a matéria. Tudo isso demostra que o interesse brasileiro pelo livro americano abarca quase todo o escopo da nossa indústria editora.

Assombra, realmente, o número de obras traduzidas num prazo relativamente curto. Até 1946, o total, em todos os gêneros literários - excluido obras do tipo de Nick Carter e os manuais técnicos e agrícolas em geral- excede mais de 650 livros diferentes, tendo sido a grande maioria traduzida de 1940 para cá. De fato o número compara mais do que favoravelmente com o número traduzido para o espanhol, que alcança presentemente a mais de 1200. O total é realmente considerável si levarmos em conta o fato de que foram omitidas na bibliografia muitas obras traduzidas e publicadas em 
Portugal que não me compete incluir por eu ter tido acesso a poucas fontes bibliográficas lusitanas. É de assombrar também, em vista da grande carestia do papel e de outros obstáculos consequentes da guerra; mas pode-se dizer que graças a essa mesma guerra que fechou o mercado europeu ao livreiro brasileiro, estreitaram-se concomitantemente as relações entre as casas editoras norteamericanas e brasileiras, aproximação favorecida e apoiada por ambos govêrnos.

E interessante percorrer os nomes de alguns autores americanos cujas obras foram traduzidas recentemente (1940-1948) para o português. Depois dos nomes segue uma cifra indicativa do número de obras traduzidas: Louis Bromfield (10), Pearl Buck (8) -mais do que em espanhol, Erskine Caldwell (5), Dos Passos (3), Lloyd Douglas (6) - de quem não tenho informação sôbre traduções em espanhol, Dreiser (3), Edna Ferber (3), Rachel Field (3), Waldo Frank (1) - que acaba de aparecer, sendo o autor muito menos conhecido do que em espanhol, Hemingway (3), Sinclair Lewis (1), Saroyan (1), Upton Sinclair (6) - em comparação com 17 obras em espanhol, e Steinbeck (8). Não me refiro aquí a certos "bestsellers" dos últimos anos, que como Fruta estranha de Lillian Smith e Entre o amor e o pecado (Forever amber) de Kathleen Winsor, começam a aparecer no Brasil quase que simultâneamente com a primeira edição americana. Esta prática tornar-se-á provavelmente regular, de agora em diante, em vista dos entendimentos entre algumas casas editoras brasileiras e americanas que concordaram na troca de cópias dos manuscritos antes da sua primeira publicação.

Convem ainda chamar atenção para o fato de que, entre os nossos clássicos e modernos, faltam alguns que até hoje não foram traduzidos para o português. E de estranhar especialmente a completa ausência de obras — não me refiro a poemas ou obràs curtas- dos seguintes autores: Sherwood Anderson, Richard Henry Dana, Lafcadio Hearn, O Henry, Eugene O'Neill, Washington Irving — apenas duas traduzidas e só em 1943, Thoreau, Bret Harte, e James T. Farrell. Apesar dêstes e outros que não aparecem, pode-se dizer que o brasileiro está mais ou menos ao par da nossa melhor produção literária.

Também é interessante fixar a atenção, um momento, na lista dos nomes dos tradutores. Dentre êles o mais conhecido será tal vez Monteiro Lobato (1886-1948), o mais popular entre os escritores 
de livros infantis do Brasil, senão de tôda América, conteur notável, fundador da indústria do livro brasileiro - para citar somente alguns poucos títulos a que tem direito; Manuel Bandeira- reconhecido poeta e acadêmico; Tristão de Athayde e Sérgio Milliet — ambos dos melhores críticos e estetas atuais; o contista e dramaturgo Raimundo Magalhães Júnior; Fernando Tude de Souza, um dos mais ativos e dedicados jovens educadores de hoje, que tem a seu crédito a tradução de mais de trinta obras americanas; e o jovem crítico mineiro Oscar Mendes, tradutor, com Milton Amado, das obras completas de Poe. Mas é justo observar que êstes, e outros, são muito mais do que apenas tradutores porque para êles a tradução é a maneira mais fecunda de tornar conhecidas, entre os seus compatriotas, as nossas figuras de relêvo que têm para o Brasil uma mensagem valiosa. Por isso, vemos que o brilhante articulista democrático do Correio da manhã, Carlos Lacerda, se dedica com fervor especial à obra e à vida de nosso Jefferson. Era de esperar que um Graciliano Ramos se interessasse pelas Memórias de Booker T. Washington, e também que outro célebre romancista do grupo nordestino, Raquel de Queiroz, se entusiasmasse pelos quadros de terra sêca tão universalmente conhecidos, de nossa Pearl Buck.

Infelizmente é pequeno o total de livros por êles traduzidos, pequeno demais para garantir, em geral, qualidade uniforme nas traduções. Há casos mesmo notórios, especialmente no campo das ciências e da medicina, de livros imperdoavelmente mutilados no seu trajeto do inglês para o português. Há muito tempo que se publica semanalmente no Diário de notícias do Rio, uma coluna intitulada "A margem das tradıções," na qual são expostos alguns dos erros e deslizes, ainda por demais frequentes, em obras traduzidas para o português. Qualquer um dêsses artigos merece bem ser lido. Em maio de 1946, por exemplo, saiu uma crítica de um livro de Upton Sinclair, O fim do mundo, publicado por Olympio em 1941. O autor do artigo contrista-se ter de criticá-lo, tratando-se de trabalho assinado por nome tão conhecido nas letras brasileiras como é o de Lúcio Cardoso. Defende-se dizendo: "Mas, como não é menos ilustre o do autor do romance e como o trabalho do tradutor ... e totalmente desprimoroso, é nossa tarefa criticá-lo, apontando-lhe os senóes, vários dêles graves e alguns até risíveis." Então generosamente elogia as traduções espanholas: "Aquí não se sonha com aquela natu- 
ralidade de linguagem que se nota nas traduções castelhanas de livros ingleses, traduções que mais parecem livros originais, tão cerradamente castelhanas são elas, sem nenhum travo da língua do texto primitivo... Mas ao menos decência nos periodos, ao menos sentido, o sentido que lá está, vivo e fresco, no inglês flutente de Upton Sinclair!" Vejamos alguns exemplos: onde Sinclair diz: "His mother would be waiting in their suite," lê-se en português: "... a mãe estaria à espera dêste com pessoas de sua predileção;" "flowerbed" sae "leito de flores," em vez de "canteiro de jardim" ou "alegrete," - aquí o nosso crítico faz o seguinte aparte: "Nêsse andar, acabara vertendo o inglês 'horseshoe' por 'sapato de cavalo'." Para quem chega a tal, é natural que a baronesa de Sinclair, que tinha "one of those henna heads" por usar nos cabelos uma tintura vermelha, ostentasse parra o nosso desrepeitoso tradutor "uma cabeça de hiena!"

Mas é de estrita justiça acrescentar que o livro que comentamos foi traduzido para o português em 1941 e que desde então vem-se notando um esfôrço geral considerável, no sentido de melhorar as traduções. Ai está o ótimo exemplo dado por certos ministérios do govêrno, contratando como tradutores e como técnicos pessoas as mais competentes quer em agricultura ou administração pública. E uma das mais importantes casas editoras brasileiras já entrou em. entendimentos bilaterais com as nossas para assegurar melhor seleção e tradução de suas respectivas obras. Por exemplo, Érico Veríssimo serve agora como conselheiro da Cașa Macmillan e do Globo. Não quero insinuar com isto que as más traduções tenham desaparecido do mercado brasileiro, mas sim que se está procurando despertar a consciência dos livreiros de ambos países, o que já é grande coisa.

Vemos, pois, que o interesse do brasileiro pelos nossos livros não tem sido pequeno nos anos recentes. Mas vejamos agora o que êle pensa dêles. Nêste caso a nossa bibliografia quase nada revela. Até cinco anos atrás, havia apenas um ou outro estudo fragmentário sôbre uma dada fase de nossa literatura. ${ }^{5}$ Entre êles, o mais interessante e ao mesmo tempo o mais antigo que conheço, é o breve ensaio intitulado "Nota sôbre a literatura da América do Norte," da autoria do célebre mulato sergipano Tobias Barreto (1839-1889) escrito em $1886 .{ }^{6}$ Mesmo uma olhadela rápida na obra dêste filósofo e poeta liberal revela a sua fecunda familiaridade com a vida 
espiritual inglesa e americana, adquirida, segundo o seu devotado amigo e redator, Sylvio Romero, através da leitura "dos melhores autores, já na própria língua e já principalmente em traduções alemães." " Por isso, não emite juizo ocioso quando se sente forçado a admitir que "um bom livro escrito em inglês é hoje, na maioria dos casos, um livro americano." Acha que, no domínio das belas letras, a América realiza "alguma cousa de semelhante à colossal concurrência dêsse país no dominio material. A América já fornece uma grande parte da nutrição da Europa: dá-lhe o seu barato petróleo, dá-lhe a sua luz elétrica." Isto em 1886. Acha ainda que a nossa literatura daquela época assumia "cada vez mais un caráter nacional," a deixar-se entrever jả uma diferenciação nacional nos escritores precedentes mesmo como Longfellow, Bryant, Poe, Irving, e "até o Niestor dos homens da pena na América - Benjamin Franklin." Para êle "a poesia americana se assinala por un traço preponderantemente idealístico... Como em nenhum outro país, a poesia alí é uma missão e aos poetas americanos deve-se dar sincero testemunho de haverem até hoje cumprido essa missão cultural com tôda a consciência da sua importância." E termina profetizando um futuro igualmente brilhante para a nossa América no campo estético-espiritual: "Uma nação, por conseguinte, cujo materialismo, tantas vêzes malsinado, admite semelhante idéia de um dever nacional para com a literatura, não tem sòmente um futuro na monstruosa aposta dos povos sôbre os pôrtos e praças comerciaes do mundo; altos destinos também se the reservam no puro domínio da vida espiritual."

A primeira e única história brasileira sôbre nossa literatura só aparece em 1944, trabalho do jovem crítico paulista Brenno Silveira, Pequena história da literatura norteamericana. Realmente não é mais do que "um estudo biográfico" da nossa literatura, reduzindo-se principalmente a uma série de biografias de sessenta e um de nossos maiores vultos desde 1800 até a atualidade. Em geral bôas, oferecem, em conjunto, uma sinopse clara do que é a nossa herança literária. O autor me perdoará, pórém, reproduzir aquí a primeira frase do seu bem acolhido livro. Começa com uma referência geográfica errônea, quase equivalente a alguns dos nossos famosos e inofensivos disparates em relação à geografia do Brasil: "A literatura norteamericana começou com os primeiros escritos dos colonizadores de Jamestown, 
na Baia de Massachusetts." Apresso-me em assegurar que no livro êsse engano é apenas um acidente.

Verdade é que anteriormente já existiam as conferências de Érico Veríssimo, Viagem através da literatura americana e de Carolina Nabuco, História literária dos Estados Unidos, promovidas pelo Instituto Brasil-Estados Unidos do Rio ${ }^{8}$ e publicadas em folhetos que hoje dificilmente podem ser obtidos. Bem feitas e interessantes como são, reduzem-se principalmente ao inevitável catálogo de nomes e tendências, em parte por ser, como confessa a autora de $A$ sucessora, "tarea difícil resumir em tão curto espaço tão vasto assunto." Outros estudos mais recentes, e de maior circulação talvez, são o penetrante Ensaio de interpretação da literatura norteamericana (1945) da brilhante escritora carioca Lúcia Miguel Pereira e o conjunto de ensaios intitulado Escritores norteamericanos e outros (1943) do paulista Rolmes Barbosa, êste último comentado favoravelmente por mim na Revista iberoamericana. ${ }^{9}$ Existe também una ou outra antologia de impressões sôbre vários aspectos da nossa vida e cultura; ${ }^{10}$ mas nelas pouco há sôbre nossas letras. E para preencher essas lacunas não há nem mesmo traduções de nossa própria crítica literária, tais como as que, por exemplo, circulam no mundo espanhol, de autores como Parrington, Pattee, Trent, e Van Doren, para não mencionar outros mais recentes. Só em 1947 aparece a primeira história de nossas letras traduzida em português: A literatura dos Estados Unidos pelo profesor Morton D. Zabel, a quem me refiro mais adiante.

Mas não se deve acreditar que o interesse do brasileiro pela nossa cultura literária limite-se a êsses estudos isolados. Nos últimos anos os jornais e as revistas literárias do Brasil vêm dedicando espaço considerável à resenha e à crítica de nossos livros. Veja-se, por exemplo, o número 7 (agôsto de 1943) da Linterna verde, boletim da Sociedade Felipe d'Oliveira, o qual é dedicado, inteiro, a nosso país, ${ }^{11}$ e também os artigos de crítica citados sob os nomes dos seus autores na Bibliografia e publicados em revistas como Leitura e Anuário brasileiro de literatura e nos suplementos semanais dos grandes diários do Rio e de São Paulo. Apesar de tudo, essa crítica é pouca na verdade, pouca até em comparação com as apreciações da nossa literatura, publicadas em espanhol.

O teatro oferece mais uma manifestação do interesse do brasileiro de hoje por outro aspecto de nossa vida cultural. Raimundo Ma- 
galhães, conhecido dramaturgo e crítico dramático, no fim de 1944 voltou dos Estados Unidos entusiasmado pelo que vira da qualidade e vitalidade de nosso teatro contemporâneo. Nos jornais, pelo rádio e em conferências divulgou a sua admiração e tentou transmitir o mesmo entusiasmo aos seus patrícios. Entre outras coisas escritas e faladas, é interessante o comentário dêle sôbre o teatro negro norteamericano: "Dos Estados Unidos têm chegado ao Teatro do Negro Brasileiro significativas manifestações de simpatia e de estímulo." Concretizando, informa que O'Neill cedeu gratis O Imperador Jones e Langston Hughes fez o mesmo em relação a $O$ imenso mar. Este também ofereceu autorização. e cópia gratis do Mulatto. Outros brasileiros também, como Carlos Lacerda por exemplo, confessam públicamente o seu apreço pelo teatro norteamericano, considerando-o dos mais interessantes do teatro moderno mundial, opinião secundada pelo erudito austríaco, Otto Maria Carpeaux, residente no Brasil.

Limitando-nos aos últimos anos, convem lembrar que a melhor peça de uma nova companhia teatral formada no Rio em 1945 -de que a primeira actriz era Bibi Ferreira, filha de Procópio- foi $O$ sétimo céu de John Golden e Austin Strong, traduzida para o português em 1938. Quase ao mesmo tempo foi apresentada também Deslumbramento (The shining hour) de John Keith Winter, obra, ao meu saber, não publicada em português, e Our. Town de Thornton Wilder, levada pelo grupo "Os Comediantes." 12 O ano 1946 foi ainda mais favorável ao teatro norteamericano quando verificamos que só no Rio foram levadas à cena meia dúzia de peças norteamericanas, entre elas algumas das mais célebres de O'Neill. ${ }^{13}$

Aquí convem chamar atenção para as atividades de divulgação literária do Instituto Cultural Brasil-Estados Unidos do Rio é de São Paulo, Porto Alegre, Bahia, Curitiba, etc. Consulte-se a lista de palestras por brasileiros e norteamericanos anunciadas na sua revista desde 1943, e veja as muitas páginas desta dedicadas à crítica e à tradução da nossa literatura. ${ }^{14} \mathrm{Da}$ mesma maneira merece atenção especial o fato de que a Universidade do Brasil no Rio, estabeleceu em 1944 uma cadeira de literatura norteamericana, exercida inicialmente pelo ilustre crítico e profesor Morton D. Zabel das Universidades de Loyola e de Chicago. Si não me engano é esta a primeira cadeira de literatura norteamericana exercida por profesor americano em tôda a Ibero-América. Pelo menos em mais outras 
duas universidades do Brasil, oferecem-se cursos sôbre literatura americana: um em Curitiba, na Universidade do Paraná, pelo Dr. Francisco Albizú, e outro no Rio, na Universidade Católica, pelos Drs. Paulo César Machado da Silva - que visitou o nosso país em 1946 e voltou admirador entusiasta de nossa vida e cultura, e Abgar Renault, profesor, crítico e tradutor de nossas letras, fino poeta mineiro, antigo diretor do Departamento Nacional de Educação e também profesor de literatura inglesa e americana na Universidade do Brasil.

Mas que se pode dizer da literatura norteamericana no Brasil de 1789 a 1940 ? E, antes de tudo, campo dificílimo de explorar para o investigador de literatura comparada, pela inacessibilidade, senão falta, de bôas coleções de livros, em geral, e de publicações periódicas, em particular. Ainda assim, não faltam dados informativos para demostrar que o brasileiro conhecia alguma cousa sôbre nossos grandes livros e sôbre os vultos proeminentes da época.

Não há dúvida que Benjamin Franklin e James Fenimore Cooper foram os primeiros a serem lidos e até os primeiros a exercerem certa influência no Brasil. No comêco, pelo menos, foram lidos mais em tradução francesa do que no original ou mesmo em português. Evidência dêste fato é o número considerável de obras francesas e de obras traduzidas para o francês que fazem parte das coleçóes de tôdas as bibliotecas públicas brasileiras. ${ }^{15}$

Seria difícil afirmar a influência ou voga de Franklin no Brasil. Para a América latina em geral, como para todo o mundo do século passado, o bom homem Ricardo representava o nascente tipo americario, prático, metódico, trabalhador, de filosofia burguesa e materialista, homem-modelo da jovem república do norte. Não é provável que os conselhos de Franklin tenham deitado raízes muito profundas no solo imperial brasileiro de outros tempos. ${ }^{16}$

Caso menos discutível e muito comentado foi o de Cooper, especialmente com relação a José de Alencar, "pai do romance brasileiro." ${ }^{17}$ David Miller Driver conclue que são os defeitos de Cooper que mais se destacam nos romances indianistas do brasileiro. ${ }^{18}$ Alencar nega dívida a Cooper, mas as provas estão na sua obra para quem quizer ver. Afrânio Peixoto acha que Gonçalves Dias também deve muito a Cooper, afirmando que o indianismo patriótico renegou 
os nobres parentes brasileiros, "para adoptar Peles Vermelhas e Caboclos, que o nativismo nos oferecia pelas penas de Cooper e de Alencar." 19

Há um fato curioso também sôbre a sorte no Brasil da Cabana do Pai Tomaz de Harriet Beecher Stowe. É o naturalista inglês Spruce ${ }^{20}$ que nos fala do seu encontro com um jovem padre português em Vila Nova no Amazonas, equidistante de Pará e Manaus. Levava o Pađre Torquato sob o braço uma tradução da célebre obra e falava acaloradamente do grave problema da escravidão nos Estados Unidos. Isto passou-se no ano 1850. Uncle Tom's Cabin apareceu em 1851. E evidente, pois, que falhou a memória de Spruce, mas verificamos pelo menos que já naquela época existia uma tradução da obra em português - dado bibliográfico que falta ainda ${ }^{21}$ - contemporânea da primeira tradução em espanhol que saiu simultâneamente em Madrid e no México em 1853. E essa desconhecida tradução portuguesa encontrava-se já no Amazonas pouco tempo depois de ter sido publicada, e era, provavelmente, um dos poucos livros existentes naquẹla vasta e despovoada região!

No artigo "Uncle Tom's Cabin in Brazil," 22 Barbara Hadley afirma que essa novela passou por várias edições brasileiras e que foi publicada em folhetim por todo o país. Além disso, assevera: "It became the subject of plays, poems, and articles as well as the inspiration for a series of novels and stories expressing hatred of slavery." Infelizmente não oferece a documentação correspondente para que se possa apreciar melhor os diversos aspectos da voga e da influência do romance. No resto do seu ensaio fala do êxito que teve a dramatização da novela. Nesta forma a obra alcançou tôdas as camadas sociais, inclusive os analfabetos, mediante diversas adaptações diferentes, feitas algumas para a alta sociedade e apresentadas por asociações abolicionistas desde o Rio até Manaus, e outras para os circos populares. Em Fortaleza, segundo a lenda, "dogmatic advocates of slavery came out of the performance ardent abolitionists, and... respectable citizens were moved to conspire for the flight of slaves from plantations." Uma adaptação popular continua até hoje no repertório do Circo Piolin. A própria senhorita Hadley assistiu a uma representação desta última num bairro popular de São Paulo, e é com uma descrição dela que termina o seu trabalho. Evidente- 
mente uma pesquisa escrupulosa traria a luz muitos dados substanciosos relativos à influência de nosso romance sôbre a ideologia, o romance, e o teatro brasileiros daquela época. ${ }^{23}$

(Continuará)

\author{
JoHN E. ENGLEKIRK, \\ Tulane University, \\ New Orleans, La.
}

\title{
N O T A S
}

1 V. Octávio Tarquinio de Sousa. "Franceses na Bahia," Correio da manhã (Rio), 31 de março de 1946.

2 Anos mais tarde, em 1889-1890, quando nasceu a República, A. J. Lamourex, redator do Rio news, "traduziu, publicou e distribuiu a Constituição dos Estados Unidos da América do Norte. Os membros da Assembleia Brasileira, que adotou a Constituição Republicana, tiveram exemplares $\mathrm{em}$ mão." V. Hugh C. Tucker. "Meus contatos com a nascente República brasileira," Revista do Instituto Brasil-Estados Unidos (Riben), v, 11, janeiro-junho de 1947 , pp. 87-89.

3 V. o que responde a Companhia Editora Nacional relativamente à popularidade dos autores estrangeiros no Brasil: "Quanto aos nossos editados estrangeiros, vários nomes devem ser citados, por serem igualmente preferidos pelo público: Edgar Rice Burroughs, o criador de Tarzan, no gênero juvenil; M. Delly, a recordista dos livros românticos; Edgar Wallace, na literatura policial; Will Durant, na filosofia; André Maurois, na biografia; Augusto Forel, em assuntos sexuais; Kipling, Jack London, Victor Pauchet, etc." Anuário brasileiro de literatura, 2, 1938, pp. 407-408.

Outro dado curioso daquela época confirma que antes da última guerra os norteamericanos eram pouco lidos no Brasil: "O povo do nosso país, embora conte com escritores nacionais notáveis, ... da-se com intensidade à leitura de autores estrangeiros traduzidos para nossa língua. Infelizmente, esas traduções nen sempre são bôas. Eloy Pontes, Mucio Leão, Agrippino Grieco (críticos) vivem verberando os tradutores incompetentes ... Gêneros de literatura inteiramente descuidados entre nos... são justamente os mais lidos, a citar dois : o policial e o romance para moças. São às dezenas de milhares os livros de Edgar Wallace, Sax Rohmer e de outros, vendidos anualmente no Brasil. Também as novelas de E. Glyn, Dyvonne, Delly. Também 'pegaram' no Brasil: André Maurois, Zweig, Axel Munthe." "Escritores estrangeiros cujas traduções são mais lidas no Brasil." Anuário brasileiro de literatura, 1, 1937, pp. 292-293.

V. também Agrippino Grieco. "Ai dos livros!" Revista do Brasil, vi, 55, pp. 137-140 (reproduzido do Jornal). 
4 Em comparação com as observações da nota anterior, sôbre a quase completa falta de interesse no livro americano nos anos de 1937 e 1938, merece referência a observação de Samuel Putnam em 1943, que afirma que naquêle ano a influência mais pronunciada sôbre o cenário literário do Brasil parecia vir dos Estados Unidos, repetindo as palavras de Broca Brito, publicadas em Cultura política: "Estamos em plena voga das letras ianques." Brazilian literature - General statement," Handbook of Latin American Studies, IX, 1943, p. 394.

Erico Veríssimo faz o seguinte resumo do assunto: "De 1935 para ca começaram a aparecer entre nos traduçôes de livros norteamericanos. A princípio foi uma onda tímida, morna e tateante que com o correr do tempo cresceu até se transformar nessa vaga avassaladora, barulhenta e sempre montante que envolve os leitores, arrebata-os, desperta-lhes paixões e faz que nossos críticos lancem ao ar esta pergunta aflita: 'Poderão ser levados a sério livros que se tornam assim tão rápida e universalmente populares?' Já tenho lido e ouvido frases como estas: 'Paremos com as traduções! Elas estão sufocando a literatura nacional.' O êxito dêsses livros que nos vêm do norte do continente não passa de triste consequência de uma propaganda cinematográfica que prefere cortejar o gôsto fácil do público, a satisfazer as exigências da bôa literatura." Viagem através da literatura americana, Rio, Instituto Brasil-Estados Unidos, s. d., p. 12.

5 V., por exemplo, o arquivo de uma revista tão recente como Aspectos (Rio, 1937-1942), "mensário de cultura e arte, no gênero o primeiro do Brasil," que tinha como "uma das suas preocupações ... a bôa amisade entre visinhos $\mathrm{e}$ não visinhos, salientemente do continente.." Fora dos artigos obrigatórios sôbre as relações culturais entre o Brasil e os Estados Unidos, dedica apenas algumas páginas biográficas a Poe - e nada mais!

6 V. "Crítica" da Bibliografia anexa.

7 "Prefácio" a Tobias Barreto, Polêmicas. Rio, Laemmert, 1901, p. xIV.

8. Outras palestras promovidas e publicadas pelo IBEU, numa série intitulada "Lições da vida americana," são: A imprensa americana $e$ sua influência no Brasil, por Nóbrega da Cunha; A contribução americana à educação, por Mário de Andrade; A ciência à serviço da agricultura americana, por Heitor Grillo; Contribuição americana à medicina, por Oswaldo. Pinheiro Campos; O cinema e sua influência na vida moderna, por Aníbal M. Machado; Influências americanas nas letras brasileiras, por Pedro Calmon; $O$ papel das artes na América, por Douglas Fairbanks Júnior; $A$ mobilização americana, por Ari Maurell Lobo; $A$ contribuição americana à filosofia da vida, por Hermes Lima; e As influências políticas angloamericanas em $R u y$ Barbosa, por Homero Pires.

9 vII, 13, novembro de 1943, pp. 197-202.

10. V. "Crítica" e "Antologias" da Bibliografia anexa. 
11 V. "Antologias" da Bibliografia anexa para um índice das matérias dêste número.

12 Thornton Wilder goza recentemente de muita popularidade no Brasil, devido, em parte pelo menos, às atividades dos vários institutos culturais, especialmente à União Cultural Brasil-Estados Unidos de São Paulo cujo Little Playhouse triunfou com a apresentação de $A$ happy journey, a 28 de novembro de 1947, e mais tarde a 15 de junho de 1948, quando do décimo aniversário da fundação da União, com a apresentação de Our Town na Escola Caetano de Campos.

13 V. Raymond Sayers, "O teatro notteamericano (1916-1946)," Riben, v, 11, janeiro-junho de 1947, pp. 68-80.

14 V. também a nota 8 desta, com referência às palestras da série "Lições da vida americana."

15 Na Biblioteca Nacional do Rio e na Biblioteca Pública da Bahia existem vários exemplares das primeiras traduções de Cooper em português, publicadas em Lisboa e em París nos anos 40 e 50 do século passado; mas o que tem maior significação e o fato de serem mais numerosas ainda as traduçốes francesas de Cooper, de quem, por exemplo, a Biblioteca Pública da Bahia possue 27 livros, traduzidos todos da edição de Pagnerre de Paris, nos anos de 1850 a 1860.

16 Não obstante, hả quem afirme o contrário. No seu artigo "Contribuição norteamericana à educação no Brasil," publicado na Revista do Instituto Brasil-Estados Unidos, IV, 10, 1946, p. 35, Francisco Venâncio Filho crê encontrar a mais remota das contribuições norteamericanas, no campo de idéias e doutrinas educacionais, no Almanaque do Bom Homem Ricardo, cuja tradução portuguesa "foi livro de leitura de escola primária no interior do Brasil, na segunda metade do século xix." Logo relata como Afrânio Peixoto viu um exemplar desta mesma edição numa exposição de livros juvenís promovida pela Biblioteca Pública de New York. Viu-o "com olhos comovidos" porque foi através dessa mesma edição que "no interior de Bahia o grande homem de letras e de ciências adquiriu o instrumento maravilhoso que the faz a sua e a nossa glória."

17 V. Isaac Goldberg. Brazilian literature, New York, Knopf, 1922, pp. 95-97; e Samuel Putnam. Marvelou's journey, New York, Knopf, 1948, pp. $149-150$.

18 The Indian in Brazilian literature, New York, Hispanic Institute in the United States, 1942, pp. 106-107. Outro comentário mais recente é de María Luisa Garzón de la Casa, intitulado La sombra de Cooper sobre el americanismo de Alencar, México, Hispanic Institute in the United States, 1944.

19 Noções de história da literatura brasileira, Rio, Francisco Alves, 1931, p. 296. O capítulo vi do livro (pp. 286-304) é dedicado a um estudo da influência americana no Brasil, ơ qual foi reproduzido em inglês, quase intacto, 
em Books abroad, 9 (Spring and Winter, 1935), pp. 3-5, 127-129, num artigo intitulado "American social and literary influences in Brazil."

20 Citado por Victor Wolfgang von Hagen. South America called them, New York, Knopf, 1945, p. 253.

21 Lúcia Miguel Pereira, "A primeira romancista americana" (v. Stowe, na Bibliografia), p. 71, refere-se a uma tradução portuguesa daquela época: "Uma tradução portuguesa de seu livro correria o Brasil, ajudando aquí a campanha abolicionista."

Samuel Putnam faz, a seguinte observação: "It is difficult to fix the exact date of the first Portuguese translation of Uncle Tom's Cabin published in Brazil, but the first version in that language was in all probability that of Francisco Ladislav d'Andrada, which appeared at Paris (Chez Rey et Ballate) in 1853." Marvelous journey, p. 247, nota 19.

22 The Inter-American, II, 10, outubro de 1943, pp. 26-27.

23 "Harriet Beecher Stowe teve influência menos duradoura, porém mais extensa, no mundo; no Brasil, como por tôda a parte, a Cabana de Pai Thomaz fez chorar e deu forças para a abolição. Aquí, mais necessária a influência, que em qualquer parte, apegados à escravidão que éramos os últimos a abandonar, os mais governados pelo sentimento que somos, entre os povos da terra." Afrânio Peixoto, obra citada, p. 297.

$\mathrm{Na}$ sua atitude e estilo insuperáveis o anti-monárquico e abolicionista Tobias Barreto confirma e comenta a observação de Afrânio Peixoto: "Eu não sou nenhum negrófago, é bem notar, mas também não sou nenhum fantas$t a$, que tenha por ventura reforçado as suas idéias abolicionistas na Cabana de pai Thomaz, ou outro qualquer livro do gênero, onde o escravo é posto em tal altura de generosidade e grandeza de ânimo, que o arcanjo Gabriel poderia respeitoso curvarse diante dêle. Eu desejo a abolição de tôdas as instituições caducas... Nêste caso está sem dúvida a escravidão. Porém entendamo-nos: nêste caso está também a monarquia." Varios escritos. Rio, Laemmert, 1900, p. 246. 
